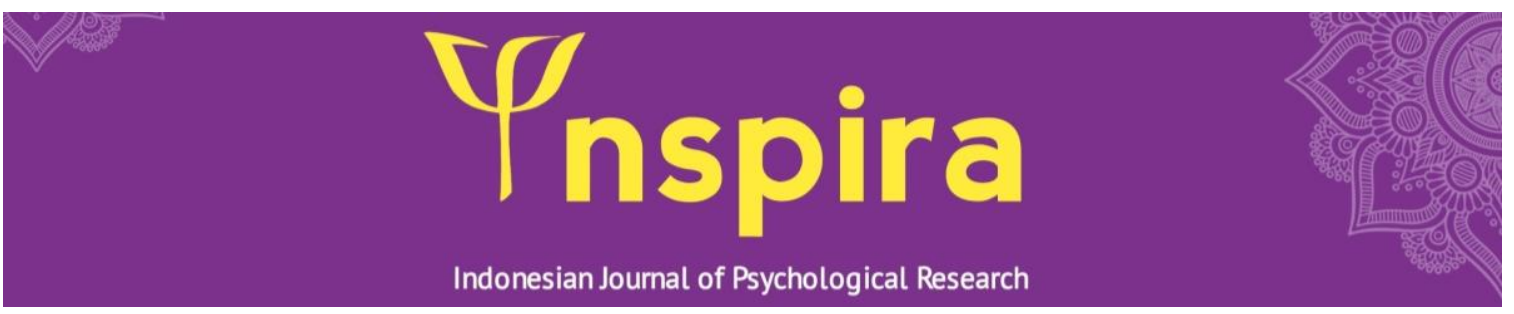

\title{
The effect of Bonyan-Method Experiential Marathon Structured Groups (BEMSG) on ego functions
}

Arash Nejatian ${ }^{1}$, Maryam Khaksar ${ }^{2}$, Alireza Zahiroddin ${ }^{3}$, Leila Azimi ${ }^{3 凶}$

${ }^{1}$ Department of Psychology, Paymeh Noor University, Tehran, Iran;

${ }^{2}$ Department of Psychology, Allameh Tabataba'i University, Tehran, Iran;

${ }^{3}$ Behavioral Sciences Research Center, Shahid Beheshti University of Medical Sciences, Tehran, Iran

\section{$\triangle$ Corresponding author:}

Leila Azimi (email: liliazimy@gmail.com)

\begin{abstract}
The present research has studied Bonyan-Method Experiential Marathon Structured Groups' efficacy on the nonclinical populations' ego functions. This study was a quasi-experimental trial with a control group. The trial group participated in the marathon group on three consecutive days (36 hours) and weekly sessions for three weeks. Then the ego function evaluation questionnaire was simultaneously given to both groups. All ego functions in the trial group showed significant growth compared to the control group. Among these, the most remarkable statistical effect size was related to "Adaptive Regression in Service of the Ego" and "Stimulus barrier." The relationship between improving ego functions and mental health can be anticipated, and steps can be taken to promote the community's mental health by using these groups.
\end{abstract}

\section{Article History: \\ Received: December 15, 2021 \\ Revised: December 23, 2021 \\ Accepted: December 29, 2021 \\ Published: December 30, 2021}

\section{Keyword:}

ego function; experiential group; large experiential group; Marathon Structured Groups

\section{How to cite (APA $7^{\text {th }}$ Edition)}

Nejatian, A., Khaksar, M., Zahiroddin, A. \& Azimi, L (2021). The effect of Bonyan-Method Experiential Marathon Structured Groups (BEMSG) on ego functions. INSPIRA: Indonesian Journal of Psychological Research, 2(2), 94-104. https://doi.org/10.32505/inspira.v2i2.3566

This is an open-access article distributed under the Creative Commons Attribution License, which permits unrestricted use, distribution, and reproduction in any medium provided the original work is properly cited. This is enabled under the terms of attribution and noncommercial usage of the material (O2021 by Arash Nejatian, Maryam Khaksar, Alireza Zahiroddin \& Leila Azimi 


\section{INTRODUCTION}

Ego functions are personality variables that can moderate stressful life events on pathological manifestations by organizing and coordinating external and internal stimuli (Basu, Basu, \& Bhattacharyya, 2004; McWilliams, 2004). Bellak et al. (1988) have defined the structure of the ego according to its adaptive functions and describe these as mental processes that regulate adaptation to the environment and individual's mental states. Providing a clinically reliable diagnostic tool based on psychodynamic models, Bellak et al. introduced a comprehensive list of ego functions representing 12 various ego functions in a clinical interview. Johnny, Stock, and Burton converted this assessment interview format into a self-report questionnaire (Juni, Stack, \& Burton, 2000). These 12 functions are: 1) Reality testing; 2) Judgment; 3) The sense of the reality of the world and the self; 4) Regulation and control of drives, effects, and impulses; 5) Object relations; 6) Thought processes; 7) Adaptive regression in the service of the ego (ARISE); 8) Defensive functioning; 9) Stimulus barrier; 10) Autonomous functions; 11) Mastercompetence; 12) Synthetic-integrative function.

Extensive research has been done to explain the relationship between the level of ego function and mental health. Davis et al. (1983) showed that low levels of ego function are associated with decreased self-esteem. Genden's study also showed that people with lower levels of ego function scored higher on the Millon Clinical Multiaxial Inventory for personality disorder and had more immature defence styles (Genden, 1995). Also, Blanck \& Blanck (1994) found that people with higher levels of ego function were more resilient in various challenges. In his study, Spielberger (1972) also found that higher levels of ego function make people less prone to anxiety. The ego functions are responsible for protecting the individual against anxiety and external stressors, while on the other hand, they are responsible for regulating emotions and managing internal mental experiences (Hagger, Wood, Stiff, \& Chatzisarant, 2010). The degree of empowerment of these functions predicts, directly and significantly, the ability to regulate emotion (Badanfiroz, Rahimian Boogar, Najee, \& Shaikhe, 2017). Studies have also shown that high levels of ego function positively correlate with social adjustment (Ziadni, Jasinski, Vief, \& Lumle, 2017). High levels of ego functions help people gain peace with others and themselves and successfully carry out their social roles in different cultural contexts (Besharat, Ramesh, \& Moghimi, 2018).

Numerous studies confirm the marathon groups' effectiveness on individual growth, such as sensitivity-training groups, human relations training groups, and large-group awareness training (LGAT). These have improved ego function, improving individuals' mental health (Fisher, Silver, Chinsky, Goff, \& Klar, 2012).

Marathon groups refer to a long, continuous, and intensive process of group confrontation, which occurs in $18,24,36$, and 72 hours sessions, depending on the group's goals. The venue usually is a quiet environment away from the disturbance of others and with minimal environmental stimuli. Marathon groups are designed and organized in very different ways. These groups' common feature is the intense confrontation with others, focusing on the hereand-now. The participants' momentary experience matters, whether based on a narrative experience from the past or created in the same group (Weigel, 2002).

Marathon groups are divided into two types: unstructured and structured. Unstructured groups are conducting the confrontation between individuals without a pre-determined plan and 
are entirely based on the experiences that occurred in the group. While in structured marathon groups, activities and processes are pre-determined for each day, and each part of the program and individuals build their own experiences and those of the group within the framework of this structure (Weigel, 2002; Bach, 1966; Pothier, 1970; Gottschalk, Pattison, \& Schafer, 1971).

Dinges \& Weigel (1971), in their study on marathon group, review the works of Mintz (1971), Bach (1967), Demos (1970), Rachman (1969-1970), Rogers (1967, 1967), Yalom (1970), and other famous group treatment organizers. They have stated that marathon groups are among the most direct, efficient, and economical ways to prevent mental health damage, such as fragmentation and meaninglessness.

Bonyan-Method Experiential Marathon Structured Groups (BEMSG) were founded in 1989 by Fereshteh Mirhashemi in the United States. It aims to transform \& grow the nonclinical population's personal and professional life (Nejatian, Khaksar, \& Azimi, 2021). BEMSG groups are planned in intensive programs on the last three days of the week, which align with the common trend of marathon groups (Schaefer and Galinsky, 1989). BEMSG programs' sessions start with a brief on the method's basic principles, followed by the individual and group structured experiential process and games coupled with sequential feedback. This process will develop a dynamic space for participants' respective personal experiences to become aware of their own and others' cognitive, emotional, behavioral, and habitual patterns known as a comfort zone. A breakthrough experience will occur by acknowledging this awareness, and they discover their values. Also, existential and acquired values and skills will be discovered, the space of possibilities will be opened, and the relationship with oneself, others, and the world will be established (Langar, 2014, Ghorbani, 1397, \& Sanaei-Zakir, 1395; Nejatian, Khaksar, \& Azimi, 2021).

BEMSG is formed based on the Bonyan theory of being. Genealogically this theory is the family of existential psychology theories. This theory focuses on "to be with what it is." This explanation of existence is based on the Be-Do-Have triangle and an open view of existence based on wholeness, integrity, and intentionality. The method, born of this theory, by choosing to be present here-and-now and being an observer on "how to be with what it is," while acceptance, responsibility, and commitment lead to the "effective \& productive state of being" (Nejatian, Khaksar, \& Azimi, 2021).

Although BEMSG has a history of more than 30 years, no studies have been conducted on the effect of participating in these groups on individuals' mental health and psychological performance. Given the background on the effectiveness of participating in marathon groups on participants' psychological components, this article contains research results to answer whether BEMSG groups are influential based on ego functions

\section{RESEARCH METHOD}

The number of participants was 118, where 68 were in the experimental group, and 50 were in the control group. All applicants were screened through interviews to meet the nonclinical population's criteria, and consents were signed. Standards that applied for all participants include 1) age over 20;2) minimum bachelor's degree; 3) employment; and 4) commitment to program rules. The experimental group was evaluated after the end of the BEMSG program. The control 
group was also assessed simultaneously as the experimental group without participating in the program.

The study used the Ego Function Self-Reporting Questionnaire, designed in 1973 by Leopold Bellak et al. (1988) and adapted from the original Bellak handbook by Juni et al. (2000). The questionnaire has twelve subscales for ego functions, examining each of the twelve ego functions with ten questions. The answer options for each question are never (0), sometimes (1), most of the time (2), and always (3). Internal consistency and reliability of these scales for clinical and nonclinical populations have been investigated and confirmed in various studies (Juni \& Straehle, 2002). In 2019, a study was conducted in Turkey to assess the Ego Performance Evaluation Questionnaire (EFA) with 426 participants. The study's statistical findings show that the questionnaire has good validity and reliability for Turkish society (Durmaz \& Barlas, 2019).

The present study used Cronbach's alpha test to determine the questionnaire's internal consistency. For this purpose, the questionnaire information was collected from 30 people with the same characteristics as the experimental and control groups. Cronbach's calculated alpha of this group was 0.893 , which indicates the questionnaire's optimal consistency for measuring the target population's dependent variable.

In this study, sampling was performed as available samples. The design was a quasiexperimental nonequivalent control group post-test-only method. In this design, the dependent variable is measured after the intervention and compared to two unequal groups with similar characteristics without random distribution (Bhattacherjee, 2019; Gravetter, 2009; Ferry, 2018). All participants in this study initially filled up a widespread demographic form in-person, including demographic characteristics, educational and professional status, marital status, goals of participation, history of physical and mental health problems, and possibly traumatic childhood experiences. The questioner also covered participants' reactive factors, intensity, and how they respond to these factors. Participants acknowledged and signed the rules and regulations for participation in the program. Eventually, all participants were interviewed for nonclinical screening. Sixty-eight (68) participants were selected for the experimental group, and the remaining fifty (50) were chosen as the control group.

The BEMSG was held on the last three days of the week (three 12-hour days, for 36 hours), followed by three weekly follow-up sessions to monitor and follow up the participants' experiences. The duration of the BEMSG was entirely in line with the standards of the marathon groups. The meetings were held in official and nonclinical settings. Participants follow the program's ground rules, including attending the entire program; No use of drugs, stimulants, and alcohol for three days and no smoking at the program's time and place. They were committed to the confidentiality of the participants' experiences and sharing. The program stopped for an hour and a half each day for two breaks and lunchtime, but participants did not leave the space. Upon completing the program, the three weekly follow-up sessions started, and on the third session, the ego-performance self-report evaluation questionnaire was given to the experimental and control groups.

The two-group design with post-test and the control group is a simpler version of the pretest-post-test design in which pre-test measurements are omitted (Gravetter, 2009). Shapiro-Wilk test ( $p$-value $<0.05$ ) was used to evaluate the normal distribution of variables (Bhattacherjee, 2019). In cases where the hypothesis of normality was not established for either of the two groups, nonparametric tests such as the U Mann-Whitney test were used. Pearson correlation 
statistics ( $r$ ) for nonparametric and Cohen-d for parametric tests were used for measuring the effect size (Mayers, 2019).

\section{RESULT}

The average age in the experimental group was 36.3 years. The youngest and oldest participants in this group were 23 and 61 years old, respectively. The standard deviation was calculated at 8.38. The control group's mean, minimum, and maximum age and standard deviation were $35.2,20,53$, and 7.97 , respectively. The "age" data was distributed nonparametrically in both groups, where the Mann-Whitney test showed that the two groups had no significant difference in terms of the age of participants. $70 \%$ of the sample size was women in both experimental and control groups, and 30\% were men (Table 1).

Table 1 Number of Participants in Each Group

\begin{tabular}{llll}
\multicolumn{1}{c}{ Group } & f & & \% \\
\hline Control & 50 & 42.4 & \\
Experimental & 68 & 57.6 & \\
\hline
\end{tabular}

Shapiro-Wilk test was used to evaluate the normality of research variables data distribution. In all the cases, distribution was nonparametric, except for "Adaptive Regression in the Service of the Ego" and "Stimulus Barrier," which showed the normal distribution. The independent ttest for these two variables and, in other cases, the Mann-Whitney was used (Table 2).

Table 2 Shapiro-Wilk test output of research variables

\begin{tabular}{|c|c|c|c|c|}
\hline \multirow{2}{*}{ Ego Functions } & \multirow{2}{*}{ Group } & \multicolumn{3}{|c|}{ Shapiro-Wilk } \\
\hline & & Statistic & Df & p-value \\
\hline \multirow[t]{2}{*}{ Object Relations } & Control & 0.869 & 68 & $<0.001$ \\
\hline & Experimental & 0.876 & 50 & $<0.001$ \\
\hline \multirow{2}{*}{ Reality Testing } & Control & 0.787 & 68 & $<0.001$ \\
\hline & Experimental & 0.898 & 50 & $<0.001$ \\
\hline \multirow[t]{2}{*}{ Judgment } & Control & 0.956 & 68 & 0.017 \\
\hline & Experimental & 0.969 & 50 & 0.202 \\
\hline The Sense of the Reality of the & Control & 0.923 & 68 & $<0.001$ \\
\hline World & Experimental & 0.920 & 50 & 0.002 \\
\hline Regulation and Control of & Control & 0.957 & 68 & 0.019 \\
\hline Drives, Effects and Impulses & Experimental & 0.963 & 50 & 0.124 \\
\hline \multirow[t]{2}{*}{ Thought Processes } & Control & 0.934 & 68 & 0.001 \\
\hline & Experimental & 0.947 & 50 & 0.026 \\
\hline Adaptive Regression in the & Control & 0.975 & 68 & 0.189 \\
\hline Service of the Ego (ARISE) & Experimental & 0.972 & 50 & 0.283 \\
\hline \multirow[t]{2}{*}{ Defensive Functioning } & Control & 0.935 & 68 & 0.001 \\
\hline & Experimental & 0.976 & 50 & 0.410 \\
\hline \multirow[t]{2}{*}{ Stimulus Barrier } & Control & 0.974 & 68 & 0.159 \\
\hline & Experimental & 0.976 & 50 & 0.396 \\
\hline \multirow[t]{2}{*}{ Autonomous Functioning } & Control & 0.922 & 68 & $<0.001$ \\
\hline & Experimental & 0.956 & 50 & 0.058 \\
\hline Synthetic-Integrative & Control & 0.946 & 68 & 0.005 \\
\hline Function & Experimental & 0.970 & 50 & 0.240 \\
\hline \multirow{2}{*}{ Master-competence } & Control & 0.929 & 68 & 0.001 \\
\hline & Experimental & 0.963 & 50 & 0.123 \\
\hline
\end{tabular}

A summary of the test results is given in Table 3. All ego function factors showed significant growth in the experimental group compared to the control group. 
For all 12 ego functions indicators, there is a significant difference between the control and experimental groups (at the level of 95\%). In all cases, the mean scores of the trial group were higher than the control group. However, the effect size of the BEMSG on the participants' ego functions was different. The most significant effect size is related to "Adaptive Regression in the Service of the Ego (ARISE)"-creativity ( $d>0.4$ ) and "Stimulus Barrier (SB)" ( $d>0.4)$. This high effect size shows that the mean scores of ARISE and SB in more than $80 \%$ of the control group's participants were lower than the mean scores in the trial group. In other words, participation in the BEMSG has significantly increased the amount of these factors in more than $80 \%$ of participants (McLeod, 2019). This percentage for the ego function with an average effect size is between $69 \%$ and $79 \%$, including object relations, reality testing, judgment, regulation and control of drives, effects and impulses, defensive functioning, autonomous function, and mastercompetence. In the low effect size ego functions, which included the sense of the world's reality and the self and synthetic-integrative function, changes were observed $58 \%$ to $69 \%$ of participants.

\section{Table 3 Summary of the statistics test result shows that all ego function factors had} significantly more growth in the experimental group than in the control group.

\begin{tabular}{|c|c|c|c|c|c|}
\hline \multirow{2}{*}{ Ego Function } & \multicolumn{2}{|c|}{ Mean } & \multirow{2}{*}{ Test } & \multirow{2}{*}{ p-value } & \multirow{2}{*}{ Effect Size } \\
\hline & Control & Experimental & & & \\
\hline Object relations & 9.11 & 10.32 & U Mann-Whitney & $<0.001$ & $\mathrm{r}=0.4$ \\
\hline Reality testing & 10.85 & 11.85 & U Mann-Whitney & $<0.001$ & $\mathrm{r}=0.4$ \\
\hline Judgment & 9.10 & 10.31 & U Mann-Whitney & 0.001 & $\mathrm{r}=0.4$ \\
\hline $\begin{array}{l}\text { The sense of the reality of } \\
\text { the world and the self }\end{array}$ & 11.04 & 11.57 & U Mann-Whitney & 0.046 & $\mathrm{r}=0.2$ \\
\hline $\begin{array}{l}\text { Regulation and control of } \\
\text { drives, effects, and impulses }\end{array}$ & 8.97 & 9.99 & U Mann-Whitney & 0.001 & $\mathrm{r}=0.3$ \\
\hline Thought processes & 8.33 & 9.96 & U Mann-Whitney & 0.001 & $\mathrm{r}=0.4$ \\
\hline $\begin{array}{l}\text { Adaptive regression in the } \\
\text { service of the ego (ARISE); }\end{array}$ & 6.85 & 7.79 & Independent t-test & 0.022 & $\mathrm{~d}=0.5$ \\
\hline Defensive functioning & 9.00 & 10.38 & U Mann-Whitney & $<0.001$ & $\mathrm{r}=0.4$ \\
\hline Stimulus barrier & 8.18 & 9.71 & independent t-test & $<0.001$ & $\mathrm{~d}=0.9$ \\
\hline Autonomous functions & 8.20 & 9.74 & U Mann-Whitney & 0.001 & $\mathrm{r}=0.4$ \\
\hline $\begin{array}{l}\text { Synthetic-integrative } \\
\text { function }\end{array}$ & 8.75 & 9.56 & U Mann-Whitney & 0.039 & $\mathrm{r}=0.2$ \\
\hline Master-competence & 8.88 & 10.10 & U Mann-Whitney & 0.006 & $\mathrm{r}=0.3$ \\
\hline
\end{tabular}

\section{DISCUSSION}

According to the obtained results, it can be stated that participating in the BEMSG had a significant positive effect on all ego performance indicators, which was in line with the existing background in this field. For example, in a 1980 study by Hartke, ego growth was shown following participation in marathon courses (Hartke, 1980, quoted in Fisher, 2012).

Although all twelve ego function scores in the trial group were significantly higher than the control group, the effect size was not the same among ego function indices. Among these, the most remarkable effect size was related to "Adaptive Regression in the Service of the Ego" and "Stimulus barrier." Meanwhile, "Sense of Reality and Sense of Self" shows the most negligible effect size. "Adaptive Regression in The Service of the Ego" is the capacity to let go, suspend controls, and enjoy ideas and imaginations in a state of regression to the early stages of development that thus enhances imagination, play, humor, initiative, and creativity (Bellak \& Goldsmith, 1984). 
Sometimes it is necessary to perform concerning the early stages of development to protect the mind from painful emotions. When this happens, one adapts to serve the ego (Goldstein, 1995). People need to allow themselves to regress with personality traits such as creative imagination and playfulness to cope with a problematic situation (Costa, 2020). This regression is considered adaptive if it enables the person to carry out their task. Sleeping is adaptive if snoozing gives someone the energy they need to complete the project. If a person sleeps all day to avoid work, it is inconsistent with adaptive regression (Czaja, 2011). Therefore, such adaptive regression in the service of the ego (ARISE) must be distinguished from the ego's adaptive defensive behaviors. Adaptive regressions in the ego's benefit include activities and actions that help people relieve the stresses of life and prepare for continued good performance (Sichel, 2020). The participants in BEMSG will gain a better ability to accept and welcome the situation by strengthening this ego function-Adaptive regression in the Service of the Ego.

On the other hand, the "Stimulus Barrier," as a complex ego function, shows the individuals' sensitivity or threshold to external and internal stimuli. This ego function enables the individual to adjust internal and external stimulation to maintain optimal alignment, acceptance, and adaptation. According to the results of this study, it can be said that joining BEMSG resulted in participants' higher ability to regulate their emotions. The BEMSG facilitates experiences such as the "here-and-now" and the individuals' detachment from their thoughts, feelings, and physical senses. The increase of indicators such as stimulus barrier, autonomous function, regulation and control of drivers, emotions, and impulses in participants can be related to these concepts. Krug believes that this type of presence and being in the moment helps people integrate with everyday conflicts and increase their capacity for acceptance and flexibility (Krug, 2009).

Against "Adaptive Regression in the Service of the Ego" (creativity) and the "Stimulus Barrier" that accounted for the most considerable effect in this study; The "Sense of the reality of the world and the self" and the "Synthetic-integrative function," although both had significant changes, had the slightest effect size. The "Sense of the reality of the world and the self" is the ability to feel oneself as part of the world, with a real identity and boundaries (Bellak \& Goldsmith, 1984). Although, as previously explained, this ego function score was significantly higher in the trial group than in the control group, this change was observed in a limited number of participants (58\%-69\%). Similar results also have been reported and mentioned in other studies with group programs. In a case study, Solomon (1988) attributed this to an individual's inability to communicate in a friendly manner with other participants.

It seems that participating in BEMSG increases the psychological capacity and flexibility of the ego of the participants by simultaneously enhancing the "Adaptive Regression in the Service of the Ego (creativity)" and the "Stimulus Barrier." "Psychological capacity" is an accessible psychological resource that contributes to the functioning of intra-psychological and interpersonal adjustment. Tugada \& Frederickson (2004) described ego resilience as "the ability to retreat from negative emotional experiences and adapt and resilient to changes in stressful experiences".

In explaining this, one must pay attention to the empirical nature of the BEMSG, where participants experience their feeling and thoughts and communicate them with others authentically during practical and experimental programs. This method focuses on gaining 
awareness based on the practical experience of "being with what it is" concerning oneself and others (Craig, 1986). How people participate in BEMSG reflects their encounter style in real life. According to Bugental, focusing on the interpersonal relationship in group meetings helps people to become aware of their state of being with what it is. Facing individuals with their structures informs them of their defences' consequences and stimulates their mutual will to overcome these defences (Bugental \& Bracke, 1992; Schneider, 2016). In Rollo May's words, intentionality, this revival is an important orientation that differs from rational or behavioral change. Its driving force stems from a sense of purity and includes a new path to being and choosing (May, 1994). BEMSG approach makes people aware of the consequences of resistance and their defences and discovers their values. Bradford (2007) believes that such awareness and discovery led to improved ego functions, marked by a significant change in this index in the present study results.

As in the present study, we only examined the relationship and effectiveness of participation in the BEMSG on ego functions. At last, we suggest that the mechanism of the effect of the BEMSG on various ego functions be investigated as qualitative research.

\section{CONCLUSION}

Bonyan-Method Experiential Marathon Groups, by creating the opportunity to be aware of "how to be with what is", enable people to encounter their dynamic inner psychological patterns such as ego functions. The ego functions are responsible for regulating emotions and managing internal mental experiences. High levels of ego functions help people gain peace with others and themselves and successfully carry out their social roles in different cultural contexts. Improving this program's psychological functions can effectively prevent fragmentation and meaninglessness and provide a good prognosis for promoting individual and social mental health.

\section{ACKNOWLEDGMENT}

Special thanks to From Fereshteh Mirhashemi, who openly encouraged us to carry out this project. We are also thankful to Farshid Moradian for clarifying our theoretical views on the theory, method, and foundation groups' status and coordinates. Our gratitude goes toward Bonyan volunteer players who helped us through the various stages of this research. We also would like to appreciate Carol Newsom for English editing this article. The Ethics Committee in Biomedical Research of the Research and Technology department of Shahid Beheshti University of Medical Sciences revised this study and approved the ethics code (IR.SBMU.RETECH.REC.1399.552).

\section{REFERENCES}

Bach, G. (1966). The marathon group: Intensive practice of intimate interaction. Psychological Reports, 18(3), 995-1002. https://doi.org/10.2466/pr0.1966.18.3.995

Badanfiroz, A., Rahimian Boogar, I., Najee, A., \& Shaikhe, M. (2017). Cognitive emotion regulation in students: The predictive role of ego strength and personality organization. 
Qom University of Medical Sciences Journal, 11(8), 37-45. http://journal.muq.ac.ir/article-1979-en.html

Basu, J., Basu, S., \& Bhattacharyya, S. (2004). Ego functions in relation to stressful life events and indices of psychopathology in paranoid schizophrenia. Psychological reports, 95(3_suppl), 1248-1252. https://doi.org/10.2466/pr0.95.3f.1248-1252

Basu, S., Basu, J., \& Bhattacharyya, S. (1999). Ego functions and their relationships to psychopathologies. Indian Journal of Clinical Psychology, 26, 82-87.

Bellak, L. (1988). Ego function assessment (EFA): A manual. Larchmont.

Bellak, L., \& Goldsmith, L. (1984). The broad scope of ego functions assessment. John Wiley \& Sons.

Besharat, M., Ramesh, S., \& Moghimi, E. (2018). Spiritual health mediates the relationship between ego-strength and adjustment to heart disease. Health Psychology Open, 5(1), 1-8. https://doi.org/10.1177/2055102918782176

Bhattacherjee, A. (2019). Social science research: Principles, methods, and practices. http://scholarcommons.usf.edu/oa_textbooks/3/

Blanck, G., \& Blanck, R. (1994). Ego psychology: Theory and practice. Columbia University Press.

Bradford, G. (2007). The play of unconditioned presence in existential-integrative psychotherapy. Journal of Transpersonal Psychology, 39, 23-47.

Bugental, J., \& Bracke, P. (1992). The future of existential-humanistic psychotherapy. Psychotherapy, 29, 28-33.

Clair, M., \& Wigren, J. (2000). (2000). Object relations and self-psychology: An introduction. Wadsworth.

Costa, R. (2020). Regression (Defense mechanism). In V. Zeigler-Hill, \& T. Shackelford (Eds.), Encyclopedia of personality and individual differences. Springer. https://doi.org/10.1007/978-3-319-24612-3_1422

Craig, P. (1986). Sanctuary and presence: An existential view of the therapist's contribution. The Humanistic Psychologists, 4(1), 22-28.

Czaja, M. (2011). The integration of ego psychological and cognitive behavioral interventions for first episode psychosis: strengthening the self and treating the symptoms. [Masters thesis, Smith College]. https://scholarworks.smith.edu/theses/1061

Davis, S., Bremer, S., \& Anderson, B. (1983). The interrelationships of ego strength, self-esteem, death anxiety, and gender in undergraduate college students. The Journal of General Psychology, 108(1), 55-59. https://doi.org/10.1080/00221309.1983.9711478

Dinges, N., \& Weigel, R. (1971). The marathon group: A review of practice and research. Comparative Group Studies, 2(4), 339-458. https://doi.org/10.1177/104649647100200401

Durmaz, Y., \& Barlas, G. (2019). Study of validity, reliability in accordance with Turkey conditions in ego functions assessment scale. Perspectives in Psychiatric Care. 55. https://doi.org/10.1111/ppc.12357

Ferry, B. (2018). The SAGE encyclopedia of educational research, measurement and evaluation. SAGE. 
Fisher, J., Silver, R., Chinsky, J., Goff, B., \& Klar, Y. (2012). Evaluating a large group awareness training: A longitudinal study of psychosocial effects. Springer Science \& Business Media.

Freud, A. (2018). The ego and the mechanisms of defense. Routledge.

Genden, S. (1995). Maturity and personality: A study of the relationship between developmental maturity, ego defenses, and personality disorders [Doctoral dissertation, Wayne State University].

Goldstein, E. (1995). Ego psychology and social work practice (2nd ed.). The Free Press.

Gottschalk, L., Pattison, E., \& Schafer, D. (1971). Training groups, encounter groups, sensitivity groups and group psychotherapy. California Medicine, 115(2), 87. https://pubmed.ncbi.nlm.nih.gov/18730582/

Gravetter, F. (2009). Research methods for the behavioral sciences, 3rd ed. SAGE Publications, Inc.

Hagger, M., Wood, C., Stiff, C., \& Chatzisarant, N. (2010). Ego depletion and the strength model of self-control: A meta-analysis. Psychological Bulletin, 136(4), 495. http://doi.org/10.1037/a0019486

Juni, S., \& Stack, J. (2005). Ego function as a correlate of addiction. American Journal on Addictions, 14, 83-93. https://doi.org/10.1080/10550490590899880

Juni, S., \& Straehle, M. (2002). Ego function assessment of nonclinical individuals. Psychological reports, $91(2), 679-686$. https://doi.org/10.2466/pr0.2002.91.2.679

Juni, S., Stack, J., \& Burton, J. (2000). Ego function assessment of substance abusers: Standardization and reliability. Psychological Reports, 87(3_suppl), 1185-1195. https://doi.org/10.2466/pr0.2000.87.3f.1185

Kernberg, O. (1972). Early ego integration and object relations. NYASA, 193(1), 233-247. https://doi.org/10.1111/j.1749-6632.1972.tb27840.x

Krug, O. (2009). James Bugental and Irvin Yalom: Two masters of existential therapy cultivate presence in the therapeutic encounter. Journal of Humanistic Psychology, 49(3), 329-354. https://doi.org/10.1177/0022167809334001

May, R. (1994). Existence. Jason Aronson.

Mayers, A. (2019). Introduction to statistics and SPSS in psychology. Harlow, United Kingdom: Pearson Education Limited.

McLeod, S. A. (2019). Simply psychology. https://www.simplypsychology.org/effect-size.html

McWilliams, N. (2004). Psychoanalytic psychotherapy: A practitioner's guide. Guilford Press.

Mirhashemi, F. (In Press). Bonyan: Theory and method.

Nejatian, A., Khaksar, M., \& Azimi, L. (2021). The effect of Bonyan-Method Experiential Marathon Structured Groups (BEMSG) on the elements of the Five-Factor Model of Personality. International Journal of Psychological Studies, 13(3), 56-63. https://doi.org/10.5539/ijps.v13n3p56 
Pothier, P. (1970). Marathon encounter groups: Rationale, techniques, and crucial issues. Perspectives in Psychiatric Care, 8(4), 153-159. https://doi.org/10.1111/j.17446163.1970.tb01318.x

Schneider, K. (2016). Existential-integrative therapy: Foundational implications for integrative practice. Journal of Psychotherapy Integration, 26(1), 49. https://doi.org/10.1037/a0039632

Sichel, M. (2020). Healthy regression.http://www.psybersquare.com/anxiety/panic_healthy_ regress.html

Solomon, A. (1988). Psychotherapy of a casualty from a mass therapy encounter group: A case study. Cultic Studies Journal, 5(2), 211-227.

Spielberger, C. D. (1972). Conceptual and methodological issues in anxiety research. In C. D. Spielberger (Ed.), Anxiety: Current Trends in Theory and Research (Vol. 2, pp. 481493). Academic Press. http://dx.doi.org/10.1016/B978-0-12-657402-9.50013-2.

Summers, F. (1994). Object relations theories and psychopathology: A comprehensive text. Analytic Press, Inc.

Tugade, M., \& Fredrickson, B. (2004). Resilient individuals use positive emotions to bounce back from negative emotional experiences. Journal of Personality and Social Psychology, 86(2), 320 333. https://doi.org/10.1037/0022-3514.86.2.320.

Weigel, R. (2002). The marathon encounter group--vision and reality: Exhuming the body for a last look. Consulting Psychology Journal: Practice and Research, 54(3), 186-198. https://doi.org/10.1037/1061-4087.54.3.186

Ziadni, M. S., Jasinski, M. J. Vief, G. L. \& Lumley, M. A. (2017). Alexithymia, defenses, and ego strength: Cross-sectional and longitudinal relationships with psychological wellbeing and depression. Journal of Happiness Studies, 18(6), 1799-1813. https://doi.org/10.1007/s10902-016-9800-7 